\title{
DNA Fingerprint Analysis of Roses
}

\author{
A. Vainstein and H. Ben-Meir \\ The Kennedy-Leigh Centre for Horticultural Research and The Otto Warburg Center for Biotechnology \\ in Agriculture, Faculty of Agriculture, The Hebrew University of Jerusalem, Rehovot 76-100, Israel
}

Additional index words. cultivar identification, microsatellite, minisatellite, Rosa $\times$ hybrida

\begin{abstract}
Mini- and microsatellite probes were hybridized to DNA of 24 rose (Rosa $\times$ hybrida) genotypes. The resultant DNA fingerprints were shown to be genotype-specific, thereby enabling cultivar identification at the DNA level. Restriction enzyme Dra I yielded the most informative band patterns. Full-sib family analysis of DNA fingerprints revealed 32 parental-specific bands out of the 128 observed in the parents. These bands were revealed cumulatively by phage (M13), human (33.6), and oligonucleotide (GACA) ${ }_{4}$ probes. Only one pair of these loci was found to be allelic, and no linked pairs were detected in the progeny analyzed. The probability of two offspring from this cross having identical DNA fingerprints was calculated to be $2 \times 10^{-8}$.
\end{abstract}

Roses are cultivated wherever gardening is practiced and are used as landscape and cut-flower plants throughout the world. As major contributors to the cut-flower market, roses have become an important target for breeding new varieties with novel and improved characteristics. Rose breeding and identifying new cultivars have been based on classical techniques. The currently used standard methods of characterizing new varieties suffer from limitations imposed by a narrow genetic base, environmental conditions, and age and type of tissue being analyzed (Krussmann, 1981; Kuhns and Fretz, 1978; Pierce and Brewbaker, 1973; Vainstein, 1993). Probably due to these limitations, the infringement of patents is an acute problem in floriculture.

Advances in the use of molecular genetic markers have enabled research on genetic variation at the DNA level (Haberfeld et al., 1991; Jeffreys, 1987). Mini- and microsatellite sequences have detected many loci consisting of tandem repeats of a short nucleotide sequence in the genomic DNA of various species (Jeffreys et al., 1985b; Nakamura et al., 1987; Wyman and White, 1980). Population analysis of these loci has revealed many alleles arising from variation in the number of repeats (Nakamura et al., 1987). Digesting DNA with restriction enzymes, recognizing sites outside such loci, has yielded these distinguishable alleles. Southern blot hybridization with mini- or microsatellite probes thus allows the simultaneous detection of many loci, yielding a unique band pattern called a DNA fingerprint (DFP) (Jeffreys et al., 1985a-c; Nakamura et al., 1987). Moreover, several probes can be used, and the information obtained by each one can be combined to increase the individual specificity of this approach (Jeffreys and Morton, 1987). The many potential applications of DFPs have brought about their use in various organisms, including plants. Mini- and microsatellites have been used in population genetics, parentage testing, and individual identification and for shortening breeding programs (Dallas, 1988; Hillel et al., 1990; Jeffreys and Morton, 1987; Jeffreys et al., 1985a, 1985c; Nybom et al., 1990; Sharon et al., 1992; Tzuri et al., 1991; Vassart et al., 1987). Recently, several rose genomic DNA probes revealing restriction fragment length polymorphism (RFLP) in roses have been identified and used to identify cultivars (Hubbard et al., 1992; Rajapakse et al., 1992). Random amplified polymorphic DNA (RAPD) markers have also

Received for publication 28 Oct. 1993. Accepted for publication 7 Feb. 1994. This study was supported by a grant from the Robert Szold Institute for Applied Science of the P.E.F. Israel Endowment Fund, the Israeli Ministry of Agriculture, and the Rose Growers Fund (Association of Israeli Flower Growers). We thank N. Zieslin, A. Holtzman, and R. Fischel for the plant material. The cost of publishing this paper was defrayed in part by the payment of page charges. Under postal regulations, this paper therefore must be hereby marked advertisement solely to indicate this fact. been used to identify rose cultivars (Torres et al., 1993).

In the present study, we assessed the usefulness of mini- and microsatellite sequences for identifying and breeding roses. We chose this approach since, based on the source of polymorphism, these markers reveal a larger number of polymorphic loci per probe and alleles per loci than the RFLP and RAPD markers previously used by others (Hubbard et al., 1992; Lavi et al., 1993; Rajapakse et al., 1992; Torres et al., 1993; Vainstein, 1993). DFPs of several rose genotypes were obtained and a pedigree analysis was performed with probes from different origins.

\section{Materials and Methods}

Plant material. The rose (Rosa $\times$ hybrida) plants analyzed were 'Frisco', 'Iceberg', 'Shocking Blue', and 'Betty Prior' (floribunda roses); 'Madelon', 'Maria Callas', 'Mabella', 'Lady Rose', and 'Rubaiyat' (hybrid tea roses); 'Eveline', 'The Fairy, and 'Margo Koster' (polyantha roses), and 10 offspring of a cross between 'Scarlet Knight' and 'Chrysler Imperial' (hybrid tea roses). The latter family was obtained from A. Holtsman, Givat Avia, Israel. 'Frisco', 'Madelon', and 'Eveline' were obtained from N. Zieslin, the Hebrew Univ. of Jerusalem, Israel. Other cultivars were obtained from R. Fischel, Fischel Nursery, Schadmot Dvora, Israel. All plants were grown under standard greenhouse conditions. Since roses are propagated vegetatively, all plants of a variety had identical genotypes.

DNA fingerprinting. DNA was isolated from young leaves as described by Tzuri et al. (1991) and digested with Dra I, Hinf I, Hind III, or Hae III restriction endonucleases. DNA $(10 \mu \mathrm{g})$ from each genotype was then electrophoresed in a 20-cm-long $0.8 \%(\mathrm{w} /$ v) TBE agarose gel at $30 \mathrm{~V}$ for $45 \mathrm{~h}$ and transferred to an $\mathrm{N}^{+}$filter (Hybond; Amersham, U.K.) by capillary blotting (according to manufacturer recommendations). Filters were hybridized to human-derived minisatellite probes 33.6 or 33.15 (Cellmark Diagnostics, Abingdon, England), a bacteriophage M13 probe (Boehringer Mannheim, Germany), or synthetic oligonucleotide

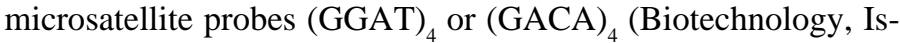
rael). Minisatellite probes were labeled with $32 \mathrm{P}-\mathrm{dCTP}$ by random priming (Feinberg and Vogelstein, 1984), and microsatellite probes were end-labeled (Sambrook et al., 1989). Hybridization was carried out at 65 and $42 \mathrm{C}$ for mini- and microsatellite probes, respectively, for $16 \mathrm{~h}$ in a solution containing $0.263 \mathrm{M}$ sodiumphosphate buffer ( $\mathrm{pH} 7.2), 7 \%(\mathrm{w} / \mathrm{v})$ sodium dodecyl sulfate (SDS), $1 \mathrm{~mm}$ ethylene-diaminetetraacetic acid (EDTA), and 1\% (w/v) bovine serum albumin (BSA). Filters were then washed once in 0.263 m sodium-phosphate buffer ( $\mathrm{pH} 7.2$ ) and $1 \%$ SDS, twice 
in 2x SSC (1x SSC: $150 \mathrm{~mm} \mathrm{NaCl,} 15$ mm sodium citrate, $\mathrm{pH} 7.0$ ), $0.1 \%$ SDS, and twice in $1 \times$ SSC, $0.1 \%$ SDS. Washes were performed for $20 \mathrm{~min}$ each at hybridization temperatures. Filters were exposed to Curix RP2 film (Agfa, Münich, Germany) at-70C for 2 to 7 days with intensifying screens (Cronex; Du Pont, Boston). All experiments were repeated at least three times, each using different DNA preparations.

Analysis of DFPs. DNA fragments $>2 \mathrm{~kb}$ in length were analyzed as previously described (Kuhnlein et al., 1990; Vainstein et al., 1991). To assess similarity between fingerprints in two DNA lanes, band sharing (BS) was calculated as $\mathrm{BS}=2\left(\mathrm{~N}_{\mathrm{ab}}\right) /\left(\mathrm{N}_{\mathrm{a}}+\mathrm{N}_{\mathrm{b}}\right)$, where $\mathrm{BS}=$ level of band sharing between lanes a and $\mathrm{b}, \mathrm{N}_{\mathrm{ab}}=$ number of bands shared by lanes a and $b, N_{a}=$ total number of bands in lane $a$, and $N_{b}=$ total number of bands in lane $b$. Bands were only compared between adjacent lanes on a gel, and only bands with different apparent molecular weights or those that differed in relative intensity by more than a factor of two were scored as polymorphic. When more than two genotypes were analyzed, BS was calculated as the average of pairwise comparisons between all genotypes.

Linkage and allelic analyses were performed as in Hillel et al. (1989). Two bands specific for one of the parents were defined as an allelic pair when either one, but only one, of the bands was always observed in each of the offspring. Two parent-specific bands were defined as linked when either both or neither, but never only one, was observed in each of the offspring.

\section{Results}

Polymorphic DFPs of roses. DFPs of three rose cultivars yielded by several restriction enzymes (Fig. 1) were analyzed to identify which enzyme revealed the most informative band pattern when used in combination with probe 33.6. The number of bands yielded by Dra I and Hind III was more than double that yielded by Hinf I or Hae III using this minisatellite probe (Table 1). The DFPs produced using Dra I were also the most polymorphic, as reflected by the low BS values. This enzyme was therefore used in subsequent experiments. The other mini- and microsatellite probes were hybridized to Dra I digests of DNA to assess their applicability to roses. All probes yielded polymorphic DFPs, each one revealing 15 to 25 bands (Fig. 2). To assess further the possibility of using DFPs to detect genetic variation, eight cultivars were analyzed. A genotype-specific band pattern was revealed for each (Fig. 3). Analysis of DFPs produced by the three probes revealed up to 83 nonshared bands between a pair ('Maria Callas' and 'Margo Koster') of genotypes (Table 2). The highest number of shared bands (40) was detected between 'Maria Callas' and 'Rubaiyat', both belonging to the hybrid tea category.

Family analysis. Genetic analysis was carried out on progeny resulting from a cross between the female parent ('Scarlet Knight')

Table 1. Average number of bands $(\mathrm{N})$ and band sharing $(\mathrm{BS})$ between DNA fingerprints (DFPs) of three rose cultivars (Mabella, Maria Callas, Lady Rose) using probe 33.6 and several restriction enzymes.

\begin{tabular}{lcccc}
\hline & \multicolumn{4}{c}{ Restriction enzyme } \\
\cline { 2 - 5 } & Dra I & Hind III & Hae III & Hinf I \\
\hline $\mathrm{N} \pm$ SE & $25.31 \pm 1.15$ & $20.35 \pm 2.56$ & $11.36 \pm 0.57$ & $7.61 \pm 1.52$ \\
$\mathrm{BS} \pm \mathrm{SE}$ & $0.55 \pm 0.06$ & $0.76 \pm 0.10$ & $0.73 \pm 0.06$ & $0.65 \pm 0.07$ \\
\hline
\end{tabular}

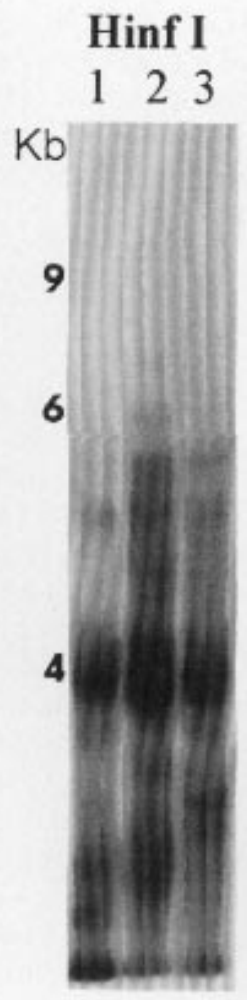

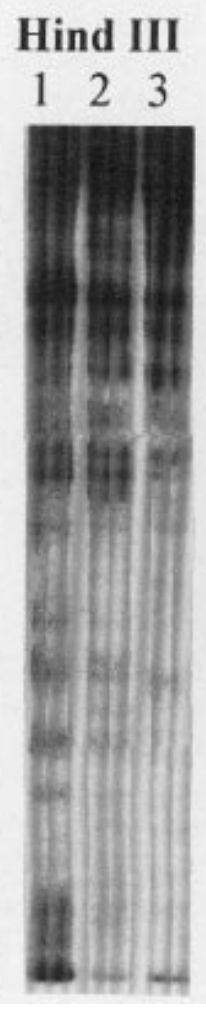

\section{Dra I}
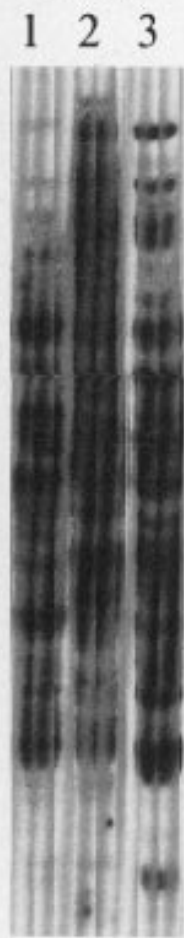

Fig. 1. DNA fingerprints (DFPs) of rose genotypes using four restriction enzymes. DNA of 'Mabella' (1), 'Maria Callas' (2), and 'Lady Rose' (3) was digested with Hinf I, Hae III, Hind III, or Dra I. DFPs were prepared using probe 33.6 as described in Materials and Methods.
M13
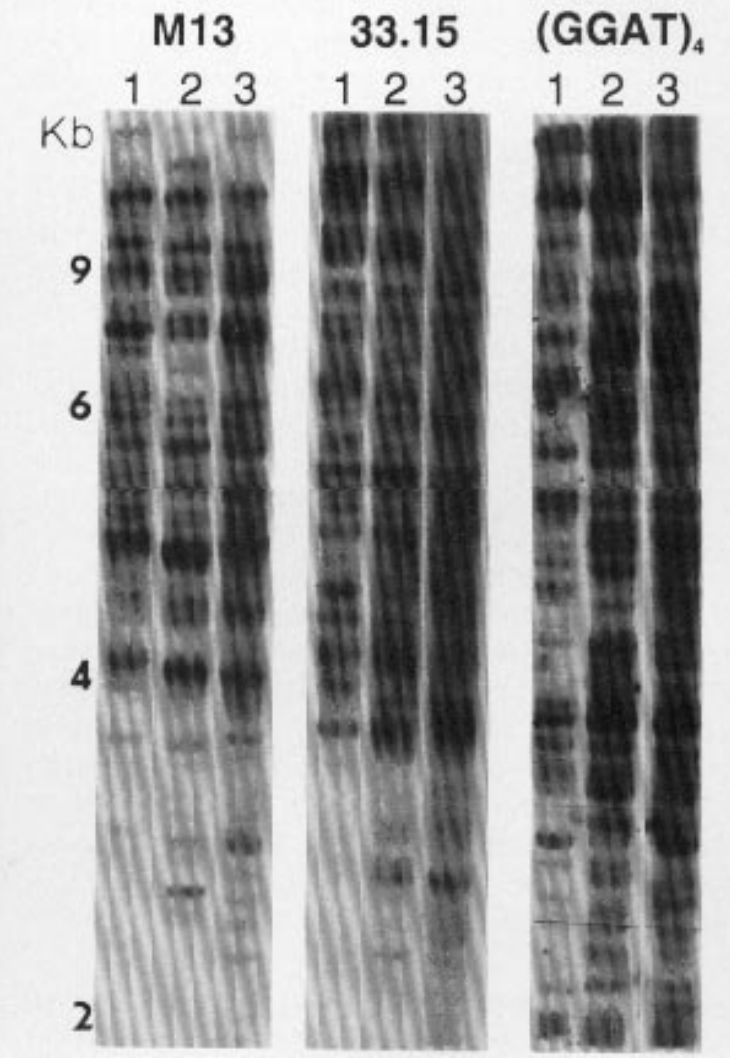

(GACA)

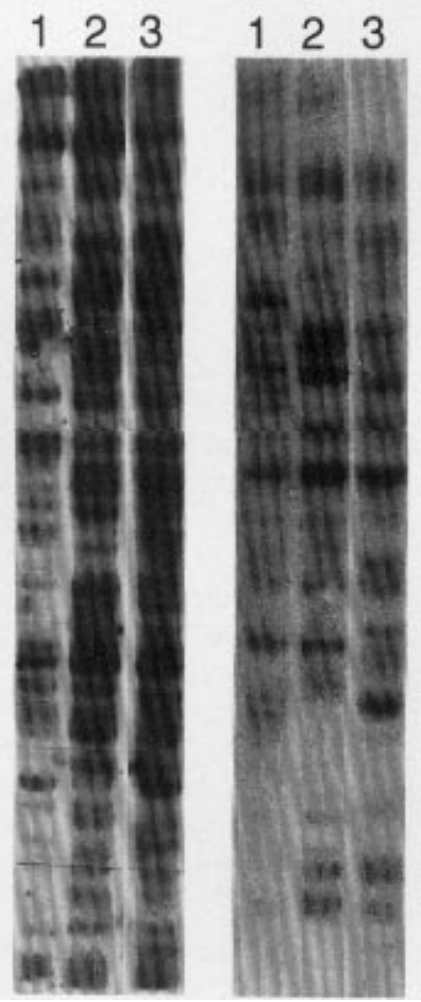

Fig. 2. DNA fingerprints (DFPs) of rose genotypes using four probes. DNA of 'Frisco' (1), 'Madelon' (2), and 'Eveline' (3) was digested with Dra I, and DFPs were prepared using probes M13, 33.15, (GGAT), and (GACA) $)_{4}$ as described in Materials and Methods. Note that the representative lanes shown are from the same gel. 


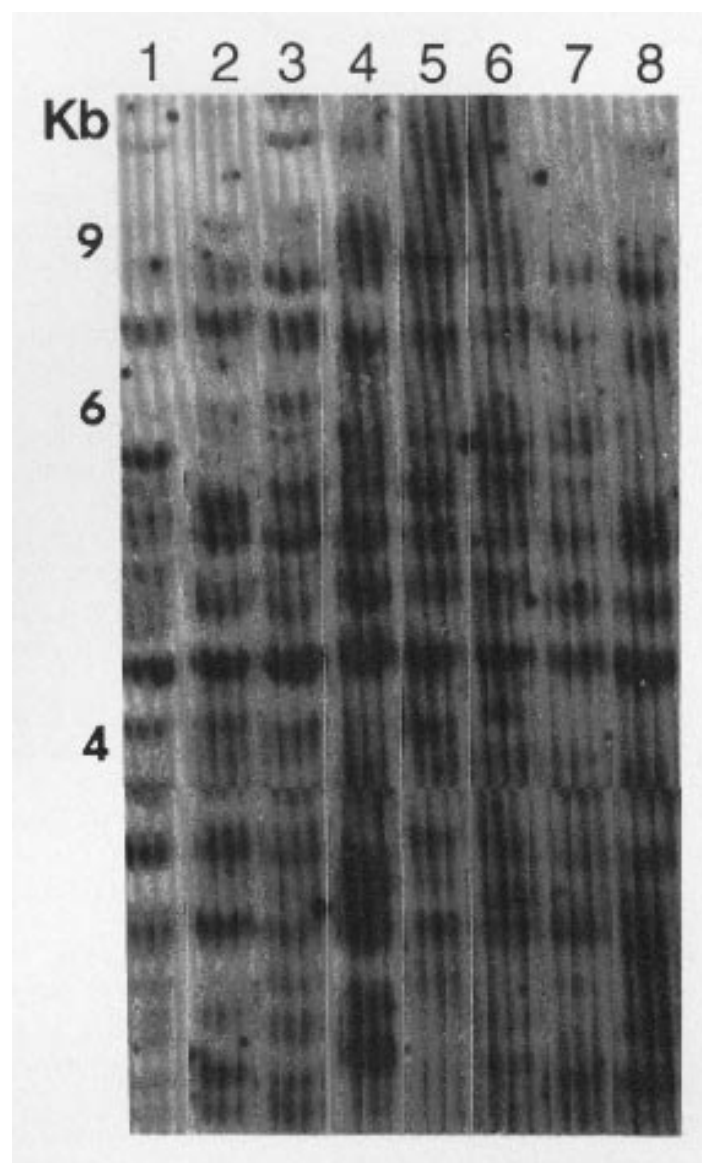

Fig. 3. DNA fingerprints (DFPs) of different rose genotypes. DNA from eight genotypes was digested with Dra I and DFPs were prepared using probe (GACA) $)_{4}$. Lanes 1-8 correspond to 'Mabella', 'Rubaiyat', 'Maria Callas', 'The Fairy', 'Margo Koster', 'Iceberg', 'Shocking Blue', and 'Betty Prior'.

Table 2. Shared and nonshared bands in rose DNA fingerprints (DFPs). ${ }^{\mathrm{z}}$

\begin{tabular}{lcccccccc}
\hline \hline & MA & RU & MC & TF & MK & IC & SB & BP \\
\hline MA & $\mathbf{5 1}$ & 36 & 37 & 14 & 15 & 20 & 27 & 23 \\
RU & 38 & $\mathbf{5 9}$ & 40 & 16 & 14 & 23 & 32 & 31 \\
MC & 39 & 41 & $\mathbf{6 2}$ & 19 & 14 & 27 & 33 & 30 \\
TF & 74 & 78 & 75 & $\mathbf{5 1}$ & 26 & 21 & 19 & 21 \\
MK & 70 & 80 & 83 & 48 & $\mathbf{4 9}$ & 19 & 18 & 20 \\
IC & 64 & 66 & 61 & 62 & 64 & $\mathbf{5 3}$ & 29 & 29 \\
SB & 48 & 46 & 47 & 64 & 64 & 46 & $\mathbf{5 1}$ & 31 \\
BP & 61 & 53 & 58 & 65 & 65 & 51 & 45 & $\mathbf{5 6}$
\end{tabular}

${ }^{\mathrm{z} A}$ pairwise analysis of rose genotype DFPs was performed. Numbers represent the sum of bands detected by probes 33.6, M13, and (GACA) 4 . Below the diagonal are nonshared bands; above the diagonal are shared bands; on the diagonal are total number of bands. MA = 'Mabella'; RU = 'Rubaiyat'; MC = 'Maria Callas'; TF = 'The Fairy'; MK = 'Margo Koster'; IC = 'Iceberg'; SB = 'Shocking Blue'; BP = 'Betty Prior'.

and a pollen donor ('Chrysler Imperial'). DFPs of the parents and 10 offspring were prepared using probes 33.6, M-13, and (GACA) . Representative DFPs are shown in Fig. 4. The total number of parental bands detected by all three probes was 128 , of which 32 were polymorphic $(\mathrm{BS}=0.75)$. The paternal contribution was 18 bands ( $56 \%$ of the polymorphic bands), while 14 bands $(44 \%)$ were maternal. Two of the paternal bands detected by probe 33.6 were allelic (Table 3). No linked parental-specific bands were detected in the progeny analyzed. Each band in the offspring could be traced back to one of the parents. No mutant band was detected

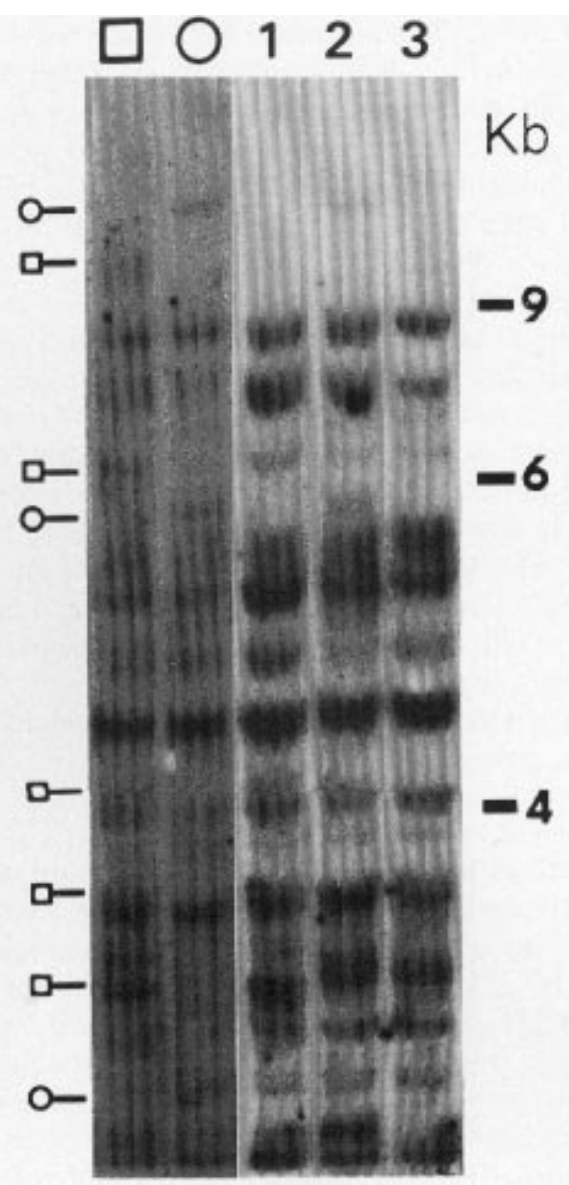

Fig. 4. DNA fingerprints (DFPs) of rose sibship. DFPs of offspring $(1,2,3)$ of a cross between 'Chrysler Imperial' $(\square)$ and 'Scarlet Knight' $(O)$ were obtained using Dra I and probe (GACA)4, as described in Materials and Methods. Representative paternal-specific polymorphic bands are indicated by $\square$, maternalspecific ones by $\bigcirc$.

Table 3. Polymorphism of DNA fingerprints (DFPs) in a rose sibship. ${ }^{\mathrm{z}}$

\begin{tabular}{lccc}
\hline \hline & \multicolumn{3}{c}{ Probes } \\
\cline { 2 - 4 } & 33.6 & M13 & $(\text { GACA })_{4}$ \\
\hline Paternal unlinked bands & 5 & 5 & 7 \\
Paternal allelic pairs & 1 & 0 & 0 \\
Maternal unlinked bands & 8 & 2 & 4 \\
Maternal allelic pairs & 0 & 0 & 0 \\
Total parental-specific bands & 14 & 7 & 11 \\
Total parental bands & 60 & 35 & 33
\end{tabular}

$\overline{{ }^{z}}$ The data was calculated for each of the three probes as described in Materials and Methods.

among the $\approx 600$ bands scored in all of the offspring analyzed, a result indicating that the mean rate of mutation to a new length allele was $<1 / 600$. The probability of two offspring having identical DFPs was calculated to be $2 \times 10^{-8}$. Calculations were based on the BS level of 0.75 found between the two parent cultivars used in this analysis and were performed as described in Jeffreys et al. (1985a).

\section{Discussion}

Human minisatellite probes 33.6 and 33.15 , the bacteriophage M13 probe, and microsatellite probes (GACA) ${ }_{4}$ and (GGAT) hybridized to polymorphic loci in roses. Not one single pair of the 
24 cultivars analyzed had identical band patterns with any of the mini- or microsatellites. Restriction enzyme Dra I yielded the most complex DFPs compared to the other enzymes analyzed. The importance of finding the suitable enzyme-probe-genus combination to obtain highly polymorphic DFPs has also been shown in studies with other plants and animals (Dallas, 1988; Hillel et al., 1989; Lavi et al., 1991a; Sharon et al., 1992; Vainstein et al., 1991).

Family analysis was carried out on progeny of a cross between 'Scarlet Knight' and 'Chrysler Imperial'. The BS values for the two parents belonging to the same category of roses (hybrid tea) was high $(\mathrm{BS}=0.75)$. This high genetic similarity was expected, since few genotypes had been used in the lengthy breeding programs to obtain cultivars with phenotypical and morphological characteristics specific to this category (Krussman, 1981; Zieslin and Moe, 1985). Progeny analysis revealed no linked bands, a result suggesting that the loci yielded by mini- and microsatellite probes are not clustered in the rose genome. The probability that two offspring from a cross between two genotypically very similar rose cultivars will have identical DFPs was calculated to be 2 $\times 10^{-8}$. This probability for misidentification is comparable to those previously determined for avocado (Lavi et al., 1991a) and poultry (Hillel et al., 1989).

DNA markers have enabled a characterization of genotypes independent of the influences of environmental growth conditions, physiological age of the plant, and the type of tissue being analyzed (Lavi et al., 1993; Vainstein, 1993). Recently, the applicability of RFLP and RAPD markers to roses has been analyzed, and both markers were shown to be potentially useful for future cultivar identification. However, to distinguish all analyzed cultivars, several probes had to be used, since each probe revealed only a very limited number of cultivar-specific bands (Hubbard et al., 1992; Rajapakse et al., 1992; Torres et al., 1993). While the number of RAPD probes is almost unlimited, only very few rose RFLP probes have been characterized to date, and obtaining additional informative RFLP probes is a lengthy task (Hubbard et al., 1992; Lavi et al., 1993; Rajapakse et al., 1992). The advantage of the approach presented here lies in the ability of mini- and microsatellite probes to simultaneously detect many polymorphic loci with many alleles (Table 2) (Jeffreys, 1987; Jeffreys et al., 1985b, 1985c; Lavi et al., 1993; Nakamura et al., 1987; Vainstein, 1993; Wyman and White, 1980). Hence, even full sibs from a cross of genetically very similar genotypes were readily distinguishable (Fig. 4, Table 3). In contrast to RAPD, the banding pattern yielded by mini- and microsatellite probes is highly reproducible. Furthermore, when methylation-insensitive restriction enzymes are used, the pattern remains unchanged, irrespective of the production origin of the cultivar or the organ analyzed (Lavi et al., 1993; Tzuri et al., 1991; Vainstein, 1993; Vainstein et al., 1991). The drawbacks of the DFP approach, i.e., its cost and the length of time and complexity involved in obtaining DFPs [due in part to the absolute necessity of using highly purified DNA (Vainstein, 1993)], are therefore largely outweighed by the amount of information they reveal.

In summary, the results presented in this study suggest that applying DFPs to roses could greatly assist in identifying cultivars. Future applications lie in the possibility of using these kinds of genetic markers in breeding programs, thereby enabling selection based on genetic linkage between DNA bands and the commercially important quantitative traits loci (Dunnington et al., 1991; Lavi et al., 1991b).

\section{Literature Cited}

Dallas, J.F. 1988. Detection of DNA fingerprints of cultivated rice by hybridization with a human minisatellite DNA probe. Proc. Natl. Acad. Sci. 85:6831-6835.

Dunnington, A.E., O. Gal, P.B. Siegal, A. Haberfeld, A. Cahaner, Y. Plotsky, U. Lavi, and J. Hillel. 1991. Deoxyribonucleic acid fingerprint comparisons between selected populations of chickens. Poultry Sci. 70:463-467.

Feinberg, A.P. and B. Vogelstein. 1984. A technique for radiolabelling DNA restriction endonuclease fragments to high specific activity. Anal. Biochem. 137:266-267.

Haberfeld, A., A. Cahaner, O. Yoffe, Y. Plotsky, and J. Hillel. 1991. DNA fingerprint of farm animals generated by micro and minisatellite DNA probes. Animal Genet. 22:299-305.

Hillel, J., Y. Plotzky, A. Haberfeld, U. Lavi, A. Cahaner, and A.J. Jeffreys. 1989. DNA fingerprints of poultry. Animal Genet. 20:145-155.

Hillel, J., T. Sharp, A. Haberfeld, A.J. Jeffreys, Y. Plotzky, A. Cahaner, and U. Lavi. 1990. DNA fingerprints applied to gene introgression in breeding programs. Genetics 124:783-789.

Hubbard, M., J.W. Kelly, S. Rajapakse, A.G. Abbott, and R.E. Ballard. 1992. Restriction fragment length polymorphisms in rose and their use for cultivar identification. HortScience 27:172-173.

Jeffreys, A.J. 1987. Highly variable mini satellites and DNA fingerprint. Biochem. Soc. Trans. 15:309-317.

Jeffreys, A.J. and D.B. Morton. 1987. DNA fingerprints of dogs and cats. Animal Genet. 18:1-15.

Jeffreys, A.J., J.F.Y. Brookfield, and R. Semenoff. 1985a. Positive identification of an immigration test case using human DNA fingerprints. Nature 317:818-819.

Jeffreys, A.J., V. Wilson, and S.L. Thein. 1985b. Hypervariable minisatellite regions in human DNA. Nature 314:67-73.

Jeffreys, A.J., V. Wilson, and S.L. Thein. 1985c. Individual specific fingerprints of human DNA. Nature 316:76-79.

Krussmann, G. 1981. The complete book of roses. Timber Press, Portland, Ore.

Kuhnlein, U., D. Zadworny, Y. Dawe, R.W. Fairfull, and J.S. Gavora. 1990. Assessment of inbreeding by DNA fingerprinting. Development of a calibration curve using defined strains of chickens. Genetics 125:161-165.

Kuhns, L.J. and T.A. Fretz. 1978. Distinguishing rose cultivars by polyacrylamide gel electrophoresis. II. Isoenzyme variation among cultivars. J. Amer. Soc. Hort. Sci. 103:509-516.

Lavi, U., P.B. Cregan, and J. Hillel. 1993. Application of DNA markers for identification and breeding of fruit trees. Plant Breeding Rev. 16:(In press).

Lavi, U., J. Hillel, A. Vainstein, E. Lahav, and D. Sharon. 1991a. Application of DNA fingerprints for identification and genetic analysis of avocado. J. Amer. Soc. Hort. Sci. 116:1078-1081.

Lavi, U., E. Lahav, A. Genizi, C. Degani, S. Gazit, and J. Hillel. 1991 b. Quantitative genetic analysis of avocado traits and cultivars. Plant Breeding 106:149-160.

Nakamura, Y., M. Leppert, P. O’Connell, R. Wollff, T. Holm, M. Culver, C. Martin, E. Fujimoto, M. Haff, E. Kumlin, and R. White. 1987. Variable number of tandem repeat (VNTR) markers for human gene mapping. Science 235:1616-1622.

Nybom, H., S.H. Ragstad, and B.A. Schaal. 1990. Genetic variation detected by use of the M13 DNA fingerprint probe in Malus, Prunus, and Rubus (Rosaceae). Theoretical Applied Genet. 79:153-156.

Pierce, L.C. and J.L. Brewbaker. 1973. Application of isozyme analysis in horticultural science. HortScience 8:17-22.

Rajapakse, S., M. Hubbard, J.W. Kelly, A.G. Abbott, and R.E. Ballard. 1992. Identification of rose cultivars by restriction fragment length polymorphisms. Sci. Hort. 52:237-245.

Sambrook, J., E.F. Fritsch, and T. Maniatis. 1989. Molecular cloning. A 
laboratory manual. 2nd ed. Cold Spring Harbor Press, Cold Spring Harbor, N.Y.

Sharon, D., J. Hillel, A. Vainstein, and U. Lavi. 1992. Application of DNA fingerprints for identification and genetic analysis of carica, papaya and other Carica species. Euphytica 62:119-126.

Torres, A.M., T. Millan, and J.I. Cubero. 1993. Identifying rose cultivars using random amplified polymorphic DNA markers. HortScience 28:333-334.

Tzuri, G., J. Hillel, U. Lavi, A. Haberfeld, and A. Vainstein. 1991. DNA fingerprints of ornamental plants. Plant Sci. 76:91-97.

Vainstein, A. 1993. Recent technical and scientific developments for the identification of varieties and the definition of minimum distances. Proc. Intl. Symp. Protection New Plant Var., Munich, Germany 6:11-20.

Vainstein, A., J. Hillel, U. Lavi, and G. Tzuri. 1991. Assessment of genetic relatedness in carnation by DNA fingerprints analysis. Euphytica 56:225-229.

Vassart, G., M. Georges, R. Monsieur, H. Brocas, A.S. Lequarre, and D. Christophe. 1987. A sequence in M13 phage detects hypervariable minisatellites in human and animal DNA. Science 235:683-684.

Wyman, A. and R. White. 1980. A highly polymorphic locus in human DNA. Proc. Natl. Acad. Sci. 77:6754-6758.

Zieslin, N. and R. Moe. 1985. Roses, p. 214-223. In: A.H. Halevy (ed.). Handbook of flowering. vol. 4. CRC Press, Boca Raton, Fla. 